\title{
Leucoencephalopathy after portacaval anastomosis in a patient with hepatic cirrhosis
}

\author{
D. L. GARDNER, A. I. S. MACPHERSON, A. F. J. MALONEY, AND J. RICHMON \\ From the University of Edinburgh and the Royal Infirmary, Edinburgh
}

Pathological changes in the central nervous system, similar to those described in Wilson's disease, have been found in patients dying in hepatic coma and when cerebral symptoms develop after shunt operations for portal hypertension (Gibson, 1963). In the following case a severe leucoencephalopathy of unusual type was demonstrated in a patient with cirrhosis of the liver who died 18 months after a portacaval anastomosis.

\section{CASE HISTORY}

The patient was a married woman aged 26 years who had complained only of vague dyspepsia before 1954 when the first haematemesis occurred. She first came under observation in April 1956, in the middle of her first pregnancy, when a more severe haematemesis also settled with conservative treatment.

The woman had been deaf since early childhood but had no previous history of jaundice, of exposure to any known hepatotoxic drug or chemical, or of alcoholic excess. The liver was not enlarged and a full range of liver function tests was normal except for prolongation of the prothrombin time of 4 seconds. The spleen was just palpable and there was moderate leucopenia and thrombocytopenia. The Wassermann reaction and Kahn test were negative. Subsequently the patient remained well during pregnancy, being delivered by elective Caesarean section in September 1956.

In February 1957 a further severe haematemesis was initially controlled by a double balloon tube, but bleeding recurred and was treated surgically by high gastric transection with stripping of the lower oesophagus and lesser and greater curvatures of the stomach to a level distal to the exit of the left gastric vein. The splenic artery was ligatured and divided, but the spleen was not removed. The liver at operation was soft in consistence. On its surface there were many nodules about $1 \mathrm{~cm}$. in diameter and biopsy (Fig. 1) showed typical portal cirrhosis.

The patient remained well till August when dental extraction was followed by excessive bleeding. Then in September 1957, when she was again found to be pregnant, another haematemesis occurred. Routine tests of hepatic function were still normal and it was decided to proceed to portacaval shunt after termination of the pregnancy. An end-to-side portacaval anastomosis was performed in March 1958, the spleen being left in situ. The gross appearance of the liver and the biopsy findings were similar to those of February 1957. The post-

operative course was uneventful and the woman remaine very well for about a year. In June 1959 she was re admitted to hospital showing, for the first time, neuro logical features. She was still able to lip read but heo attention tended to wander and she lacked interest in hep surroundings. The gait was ataxic, Rombergism was marked, and tone and tendon reflexes in the lower limb $\rho$ were increased; the plantar reflexes were flexor. There were no other neurological signs and in particular no tremor. Spider naevi and palmar erythema were nof present. The liver and spleen could be percussed to the costal margin but were not palpable. The periphera blood picture and tests of hepatic function were normal, The cerebrospinal fluid was normal in all respects, and venous blood urea, glucose, electrolytes, and ammo



FIG. 1. Hepatic portal tract showing proliferation ofñ fibroblasts in portal radical and extension of fibrous tissue among liver lobules (haematoxylin and eosin $\times 225$ ). 
were all within normal limits. An E.E.G. showed a minor dysrhythmia which was not typical of hepatic encephalopathy, and did not improve on a low-protein diet and Neomycin. There was no aminoaciduria. The serum copper and copper oxidase and the daily urinary excretion of copper were always within normal limits. The serum vitamin $\mathbf{B}_{12}$ level was also normal. In spite of empirical treatment with Parentrovite, Campolon, and later with Versene and Penicillamine, the ability to lip read decreased progressively, and ataxia, clumsiness of hand movements, and spasticity in all limbs with sustained bilateral ankle clonus became marked. By mid-October vascular naevi had developed on the upper limbs and chest and for the first time hepatic function tests showed a low level of serum albumin, impairment of bromsulphthalein clearance $(30 \%$ retention at 30 minutes), and recurrence of prolongation of the one-stage prothrombin time ( 3 to 4 seconds). A lumbar air encephalogram showed changes consistent with mild cerebral cortical atrophy.

The patient died in December 1959.

PATHOLOGICAL FINDINGS At necropsy the relevant findings were as follows:-

The liver was smaller than normal. The external and cut surfaces showed a variegated yellow-brown appearance and occasional circumscribed nodules up to about $1 \mathrm{~cm}$. in diameter but free from scarring; the consistence was uniform and firm. The portacaval anastomosis was patent. The spleen was enlarged to more than twice its normal size with a firm grey-white false capsule and many surrounding adhesions. The cut surface was purple black and there were few recognizable Malpighian bodies. The vertebral bone marrow was normal; there was no lymphadenopathy.

The fixed brain weighed 1,140 g. and showed slight symmetrical frontal lobe atrophy. Serial coronal sectioning of both cerebrums revealed slight alteration of colour in the centrum semi-ovale of both hemispheres in all sections behind the anterior commissure. This change was characterized by the presence of small ill-defined discrete or partially confluent greyish plaques which were thought to be foci of demyelination. In the medial wall of both occipital horns where these changes were most apparent, the white matter was soft and granular. The basal ganglia, cortical grey matter, ventricular system, brain-stem, and cerebellum appeared normal.

MICROSCOPICAL EXAMINATION The changes of chronic cirrhosis essentially similar to those described at the first biopsy are noted in all sections of liver examined.

The capsule of the spleen is thickened. There is slight congestion, and within the white splenic pulp there is an apparent excess of mononuclear cells mostly of lymphoblastic type. Lymphocytes and plasma cells are present in smaller numbers and occasional eosinophil polymorphs. Blood vessels are of normal size and free from amyloid.

White matter cerebrum The lesions described above are irregular foci of demyelination (Figs. 2 and 3); they are much more numerous, involve more extensive areas of white matter than was apparent macroscopically and extend in continuity into the internal capsules, cerebral peduncles, and possibly ventral pons. The lesions in all

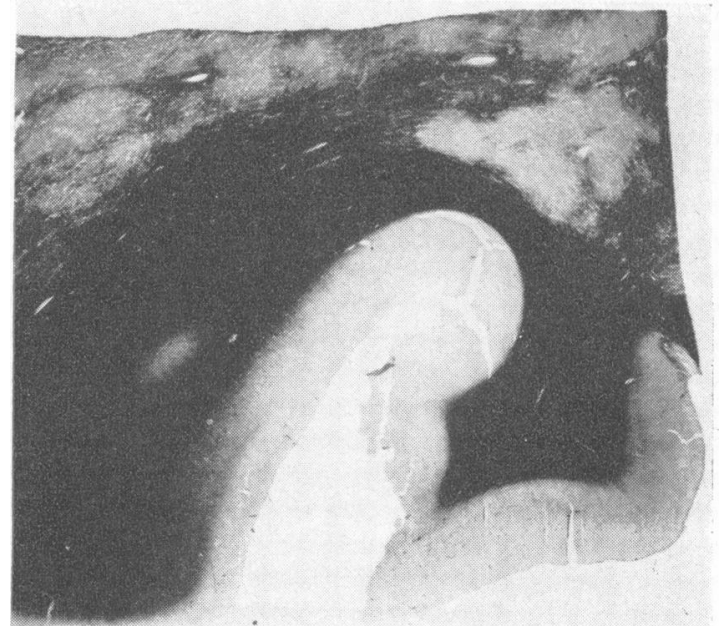

FIG. 2. Foci of demyelination in cerebral white matter. (Smith and Quigley $\times 4$ ).

areas are essentially similar but show minor differences in the degree of the reactive change. They are characterized by loosening and vacuolation of the white matter to produce a status spongiosus associated with a variable destruction of myelin tubes and, to a less extent, of axis cylinders (Figs. 4 and 5). In some areas there is practically total absence of myelin, in others variable numbers of grossly swollen, ballooned and fragmented tubes remain. Breakdown products of myelin appear as eosinophilic material in aggregates of varying size up to some $80 \mu$ in diameter, or intracellularly, presumably in histiocytes (Fig. 6). This material, a 'pre-lipid', stains positively with myelin stains and P.A.S., both in frozen and paraffin section. It also stains metachromatically with toluidine blue. In addition, sudanophilic foam cells are seen in varying numbers within the demyelinating lesions, so that the appearances are 'mixed', i.e., both metachromatic pre-lipid and sudanophilic breakdown products are present. However, the quantity of persisting breakdown products is often disproportionately small even in severely damaged areas.

A meshwork of fine and also thicker glial fibres is usually present throughout the areas of demyelination. In the centre of some lesions the fibres stain poorly either for technical reasons or due to further degenerative changes affecting the neuroglia. Astrocytes are not greatly increased in number, but moderate numbers of large cells, some resembling gemistocytes are present (Fig. 7). These cells, which are often multinucleated, have copious, pale, hyaline cytoplasm and thick branching processes (Fig. 8). Irregularities of size, shape, and chromicity are striking features in some of the nuclei, but no mitotic figures or inclusion bodies are seen. These giant cells, which are presumed to be of astrocytic origin, are confined to the demyelinated areas.

Oligodendroglial cells show no particular abnormalities apart from acute swelling and can readily be recognized, except in the most severe lesions. 


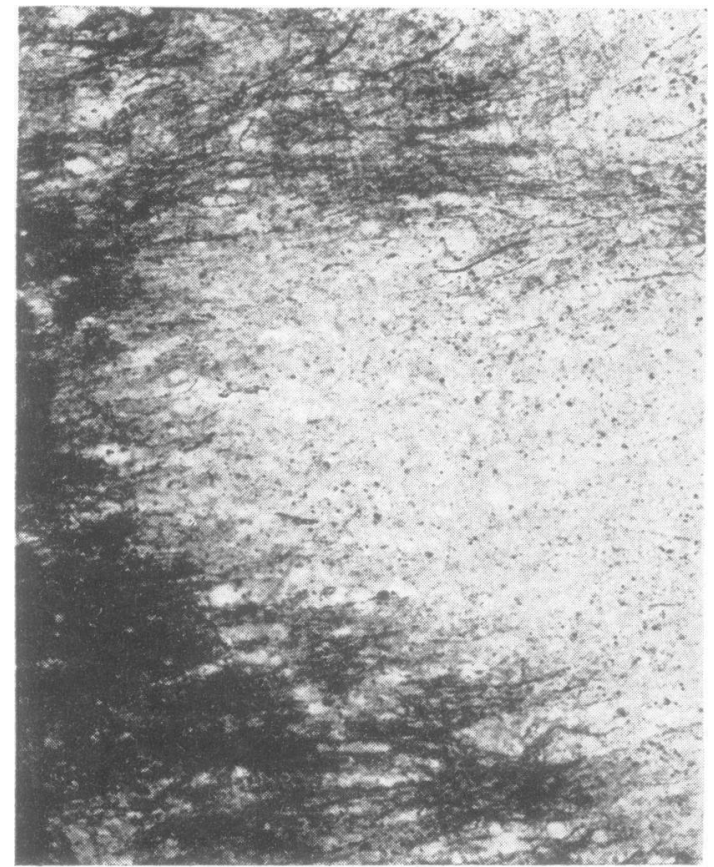

FIG. 3

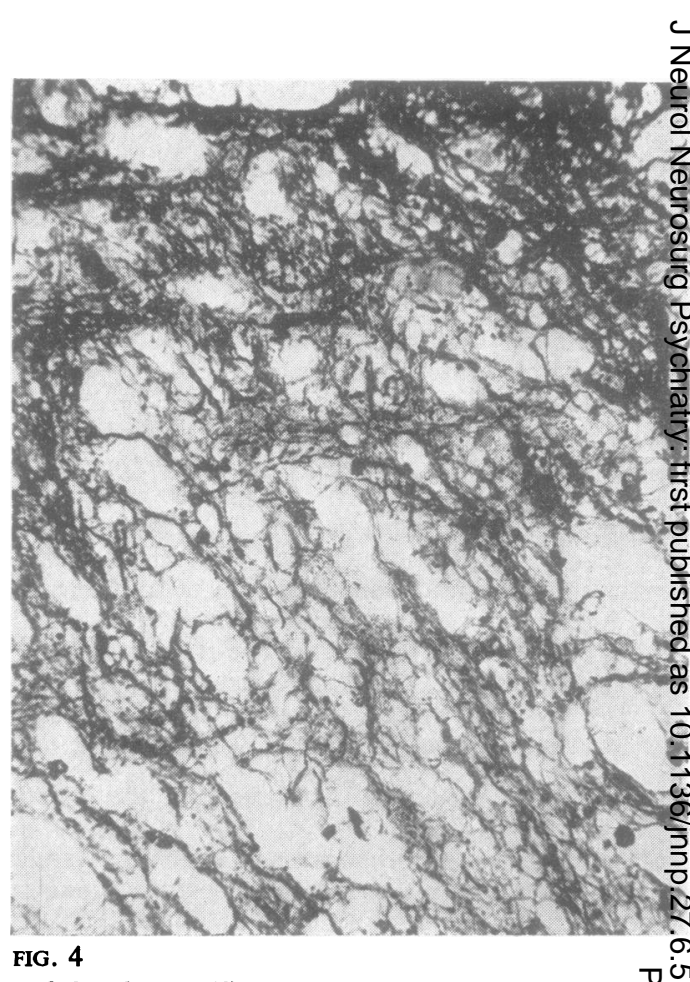

FIG. 3. Extensive demyelination in centrum semiovale (Smith and Quigley $\times 45)$.

FIG. 4. Cerebral white matter to show spongy nature of myelin degeneration (Loyez $\times 225)$.

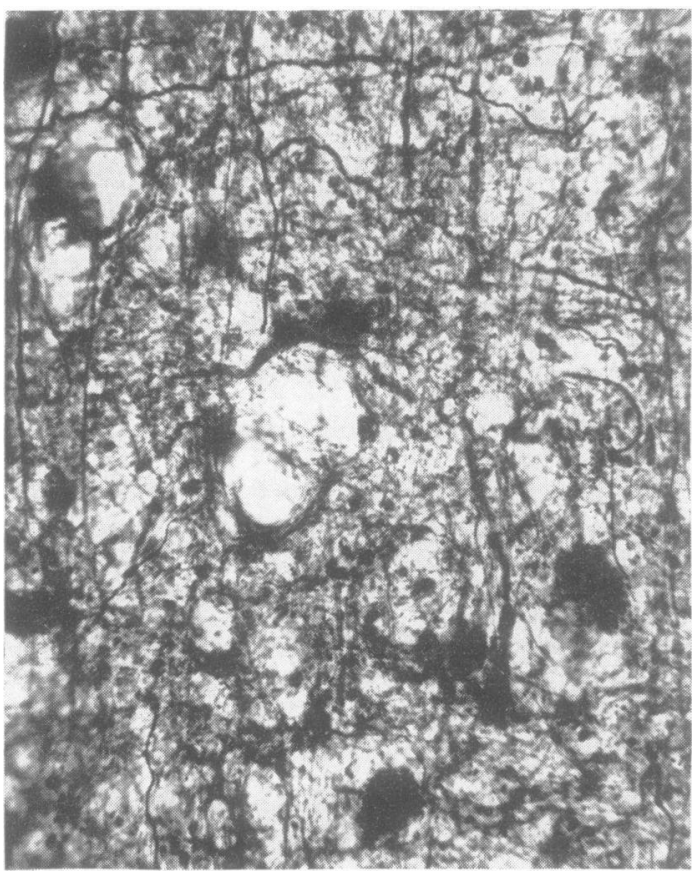

FIG. 5

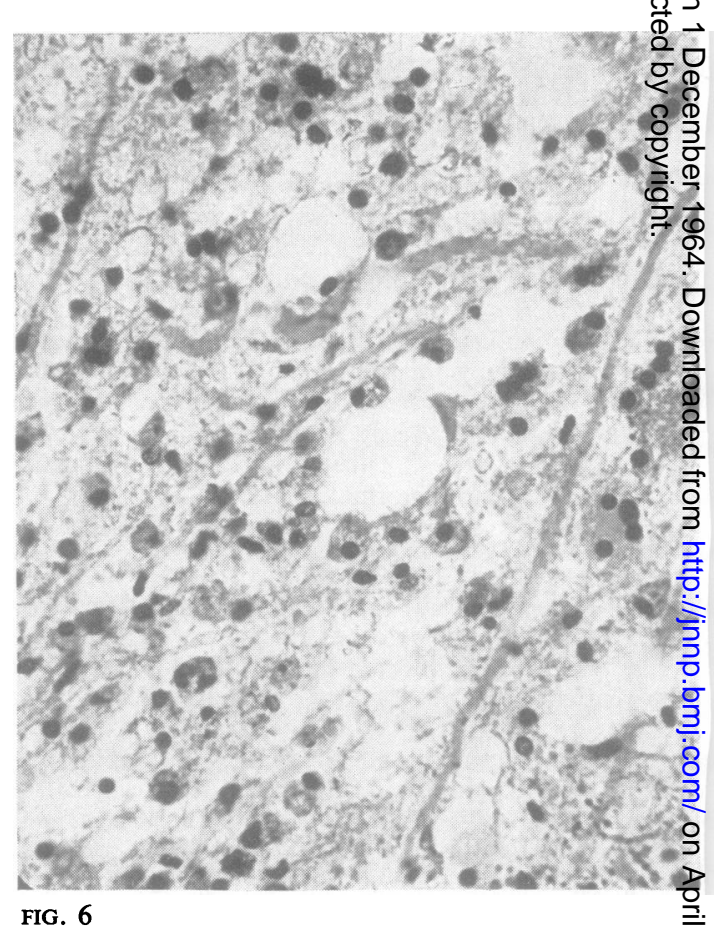

FIG. 5. Area of spongy degeneration in cerebral white matter showing relative preservation of axons (Hortega's methos for axons $\times 225$ ).

FIG. 6. Histiocytic infiltration of demyelinated zone in cerebral white matter (P.A.S. $\times 400)$. 


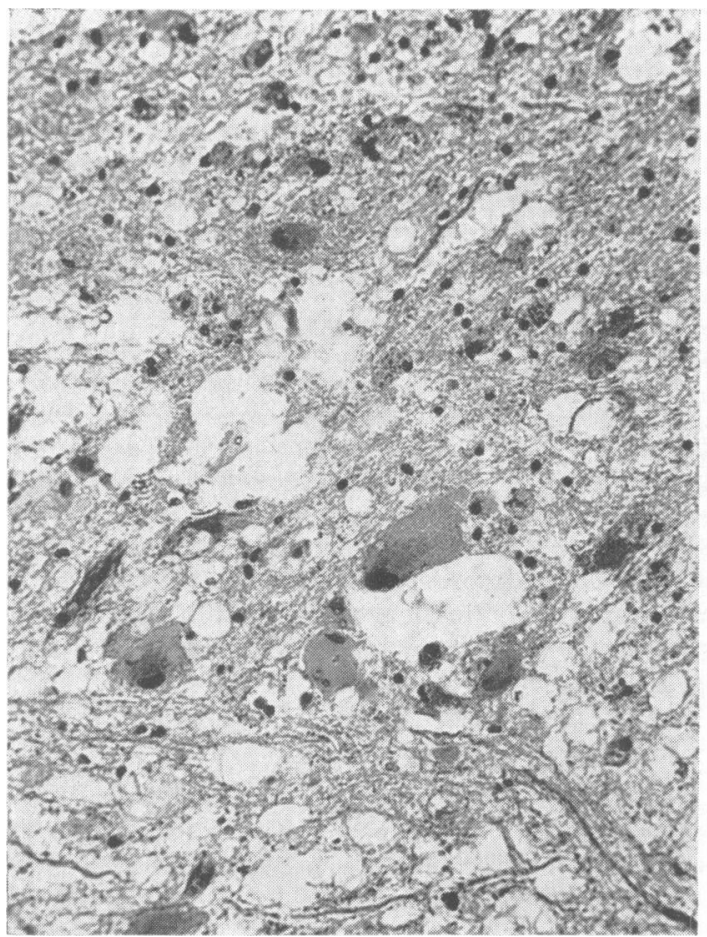

FIG. 7

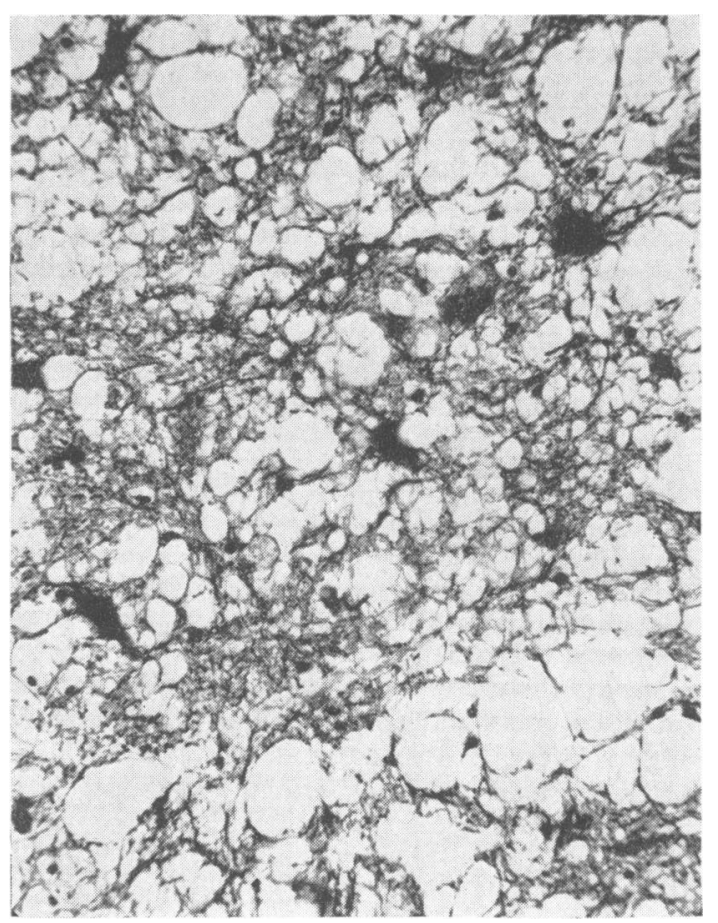

FIG. 8

FIG. 7. Neuroglial reaction to demyelination. The large cells resemble gemistocytic astrocytes.

FIG. 8. Demonstration of branching processes of large glial cells in focus of spongy demyelination (Mallory's phosphotungstic acid haematoxylin $\times 225)$.

Vascular changes are not a feature, but many of the smaller vessels within the lesions are congested and have swollen endothelium; mild perivascular cuffing with lymphocytes and sudanophilic histiocytes is occasionally seen. The demyelinated areas bear no particular relation to the blood vessels.

Rod cell proliferation occurs in some of the lesions but is not usually marked. The margins of the lesions are in general poorly defined. The surrounding white matter usually shows solitary and aggregated vacuoles, apparently devoid of content, and slight gliosis. The arcuate fibres tend to be spared.

Grey matter cerebrum In the deeper layers of the cortex and in the basal ganglia there is a slight increase in the number of astrocytic nuclei. Alzheimer type II cells are seen, particularly in the lentiform nuclei. None of the astrocytes resembles those present in the demyelinated areas described above. There is also a slight rod cell reaction. The nerve cells occasionally show shrinkage.

Mid brain Both cerebral peduncles show severe degeneration of myelin and vacuolation, the reactive changes being similar to those described above in the centrum semiovale. In the grey matter, particularly in the substantia nigra, there is an increase of astrocytes and rod cells.

Pons The changes are confined to the ventral pons.
There is partial demyelination of many of the bundles of long projection fibres and a brisk proliferation of neuroglial cells amongst the pontine nuclei. Vacuolation of affected white matter is less marked than at higher levels and there are no large astrocytes. It is probable that the changes are due more to secondary tract degeneration than to the primary demyelinating process.

Cerebellum The folia and white matter are normal. In the dentate nucleus some of the neurones appear eosinophilic, but are not enlarged, and there is slight gliosis. The leptomeninges and ependyma are normal.

Copper content of brain The copper content of the patient's cerebral cortex, white matter and basal ganglia, compared with that of a control brain which had been preserved in the same manner for a similar length of time, is shown in the Table.

\section{TABLE}

COPPER CONTENT OF PATIENT'S BRAIN COMPARED WITH THAT OF A CONTROL

Copper (mg.)/g. Wet Weight

\begin{tabular}{lccc} 
& White Matter & Cerebral Cortex & Basal Ganglia \\
\hline Control & 0.91 & 0.76 & 0.81 \\
Patient & 1.01 & 0.92 & 0.63
\end{tabular}


DISCUSSION

The neuropathological changes described in this case were unusual and are considered in respect of the presence of Alzheimer II astrocytes and the demyelinating process.

Alzheimer II cells were present in the basal ganglia and cortical grey matter, but were inconspicuous in the lesions in the white matter. These cells were first described in Wilson's disease (Hösslin and Alzheimer, 1912), but have also been observed by Adams and Foley (1953) in patients dying in hepatic coma with none of the features of Wilson's disease, in Canavan's spongy degeneration of white matter (Greenfield and Norman, 1963), and less commonly in other conditions (Brown, 1957). Therefore, though they are undoubtedly most commonly encountered in hepatic encephalopathy, they are not diagnostic of this disorder. The demyelinating process in the present case was multifocal, unrelated to blood vessels, and widespread in the central white matter, internal capsules, and cerebral peduncles. It was characterized by a peculiar spongy degeneration, the appearances suggesting that, preceding or accompanying the breakdown of myelin, fluid had accumulated in the white matter pushing aside the myelinated fibres to produce large, irregular, empty spaces. Myelin breakdown products of the metachromatic and neutral fat variety were present in small amounts and there was an unusual astrocytosis associated with some glial fibre formation. The presence of abnormal glial cells in multiple areas of demyelination was reminiscent of the progressive multifocal leucoencephalopathy associated with disorders of the reticulo-endothelial system (Aström, Mancall, and Richardson, 1958; Cavanagh, Greenbaum, Marshall, and Rubinstein, 1959). Dr. Cavanagh, however, who kindly reviewed our material, emphasized several differences, namely, that (1) the myelin loss was rarely complete; (2) it was often more apparent than real due to the severe vacuolation; and (3) the glial cell abnormality was less marked. Spongy demyelination is also seen in Canavan's disease. However, this condition has been described only in infancy and early childhood, the brain is characteristically enlarged, and the alteration in the white matter is diffuse and may involve the deeper layers of the cortex. The present case differed from the other recognized types of diffuse sclerosis principally in the remarkable spongy change, although the tendency for the foci of demyelination to stop short of the cortex, often sparing the arcuate fibres, was quite striking. Cerebral subacute combined degeneration was also considered, but was excluded because the serum vitamin $\mathbf{B}_{12}$ level was normal.

Status spongiosus may be seen in the brain in hepato-lenticular degeneration (Barnes and Hurst $\bar{Z}$ 1926; Leigh and Card, 1949) and in hepatic cirrhosis and portal hypertension in which large portal-o systemic shunts have formed naturally (Baltzan Olszewski and Zervas, 1957) or been made surgically (Gibson, 1963). At necropsy in the case reported byen Baltzan and his colleagues there was an occlusion of the portal vein with a big anastomotic vein in the place of the coronary vein; cirrhotic changes in the liver were not striking. However, the terminal illness: had been marked by gross abnormalities in the tests? of hepatic function. Status spongiosus was recog은 nized macroscopically in Gibson's case as a $3 \mathrm{~mm}$ 흘. thick 'dark brown spongy semi-gelatinous zone' at? the junction of cortex and white matter. It may bea seen in the putamen in Wilson's disease, but fres quently no macroscopic changes are observed andthe alteration is only recognized histologically. The sites of predilection appear to be in the white matter $\vec{\omega}$ of the superior and middle frontal gyri, the deep? cortical layers in the region of the pre-central gyrus, and in the striatum. In other varieties of liver disease status spongiosus appears to be less common. Fibrillary gliosis was not a feature in Gibson's case and the astrocytic increase was of protoplasmic and A $\bar{z}_{0}-\mathrm{E}_{\mathrm{O}}$ heimer II type.

Widespread demyelination and nerve cell dama $\mathrm{e}^{?}$ were reported in eight out of 18 cases of severe liver disease by Baker (1949). The demyelination, which was often extensive, differed from our case in thagite commenced around blood vessels. It is also remarked that there was no evidence of any reactive change fo $^{\mathbb{D}}$ the myelin loss. No compound granular corpusctes $\overrightarrow{0}$ were present and vacuolation was rarely obvious. His patients had not shown clinical evidence of chronic cerebral disorder and the neuropathologicalo changes were assumed to be terminal. If the patients so affected had survived for longer periods, it iso probable that reactive cellular changes would have taken place in the white matter. However, as the lesions were clearly related to blood vessels, it is un- $\overrightarrow{\overrightarrow{0}}$ likely that the resultant histological picture would have resembled that found in the present case.

In our experience, when neuropsychiatric symptoms have followed portacaval anastomosis the interval between operation and their onset has beeno a matter of weeks and the function of the liver before operation has been known to be poor. In the present case, tests of hepatic function showed no abnormalityo before portacaval anastomosis (though severe portaß cirrhosis was evident at operation and on biopsy) and, as in the case of Baltzan et al. (1957), showed nos measurable deterioration till shortly before death.으. No evidence of Wilson's disease or haemosiderosis was found in life or after death. Nitrogen metabolism. was not demonstrably affected throughout most of $\mathbb{O}^{\circ}$ 
her illness and no elevation of blood ammonia or gross deficiency of vitamins was detected. Though the patient had been deaf from childhood, no defect of the central nervous system was discovered before operation and none to account for it at necropsy. Hence, in spite of the severity of the neuropathological changes, it seems reasonable to assume that they occurred during the year before death and were consequent on the portacaval anastomosis.

\section{SUMMARY}

A case is reported of a severe leucoencephalopathy in a patient with cirrhosis of the liver who was pregnant twice during the course of her illness, had recurrent haematemeses, and was treated first by gastric transection and then by portacaval anastomosis. She died 18 months later. The findings in the brain at necropsy are detailed and differences from reports of other similar cases noted.

We wish to thank Dr. S. L. Tompsett, Northern General Hospital, Edinburgh, for estimations of the copper content of the patient's brain after necropsy and colleagues in the Departments of Clinical Chemistry, Haematology, Pathology, and Radiodiagnosis, Royal
Infirmary, Edinburgh, for their assistance with the investigations that were undertaken.

\section{REFERENCES}

Adams, R. D., and Foley, J. M. (1953). The neurological disorder associated with liver disease. Res. Publ. Ass. nerv. ment. Dis., 32, 198-237.

Aström, K. E., Mancall, E. L., and Richardson, E. P. (1958). Progressive multifocal leuko-encephalopathy; a hitherto unrecognized complication of chronic lymphatic leukaemia and Hodgkin's disease. Brain, 81, 93-111.

Baker, A. B. (1949). The central nervous system in hepatic disease. J. Neuropath. exp. Neurol., 8, 283-294.

Baltzan, M. A., Olszewski, J. and Zervas, N. (1957). Chronic portohepatic encephalopathy. Ibid., 16, 410-421.

Barnes, S., and Hurst, E. W. (1926). A further note on hepato-lenticular degeneration. Brain, 49, 36-60.

Brown, I. A. (1957). Liver-brain Relationships, p. 137. Thomas, Springfield, Illinois.

Cavanagh, J. B., Greenbaum, D., Marshall, A. H. E. and Rubinstein, L. J. (1959). Cerebral demyelination associated with disorders of the reticuloendothelial system. Lancet, 2, 524-529.

Gibson, J. B. (1963). Encephalopathy after portacaval shunt. Brit. med. J., 1, 1652-1655.

Greenfield, J. G., and Norman, R. M. (1963). In Greenfield's Neuropathology, 2nd ed. by W. Blackwood, W. H. McMenemey, A. Meyer, R. M. Norman, and D. S. Russell, pp. 515-516. Arnold, London.

Hösslin, C. von, and Alzheimer, A. (1912). Ein Beitrag zur Klinik und pathologischen Anatomie der Westphal-Strümpellschen Pseudosklerose. Z. ges. Neurol. Psychiat., 8, 183-209.

Leigh, A. D., and Card, W. I. (1949). Hepato-lenticular degeneration; a case associated with postero-lateral column degeneration. J. Neuropath. exp. Neurol., 8, 338-346. 